\title{
Causes of Morbidity and Mortality Following Intracranial Aneurysm Rupture
}

\author{
J. Max Findlay and Gail M. Deagle
}

\begin{abstract}
Objective: To determine the current recovery rates and causes for morbidity and mortality in patients suffering aneurysmal subarachnoid hemorrhage (SAH). Methods: We reviewed a recent consecutive series of 95 patients with ruptured intracranial aneurysms who presented to our hospital between 1994 and 1995. When administered, active treatment consisted of early surgery for aneurysm clipping and aggressive prevention and treatment of SAH-related complications. Results: Eighty-eight (93\%) of the patients were admitted within 24 hours of rupture. One-quarter of the patients in this series did not undergo aneurysm clipping due to poor neurological condition on presentation. Of the 75 patients initially considered for active treatment, $83 \%$ underwent surgery within 48 hours of rupture, all received nimodipine, $16 \%$ received tissue plasminogen activator to lyse subarachnoid or intraventricular clots, $40 \%$ underwent hypertensive treatment, and $7 \%$ underwent transluminal balloon angioplasty for vasospasm. At one year followup, $29 \%$ of patients had died, $7 \%$ had severe disabilities, $13 \%$ had moderate disabilities, $51 \%$ had made a good recovery, and $64 \%$ of all surviving patients had returned to their previous work status. Primary and contributing causes of death and disability, affecting 47 patients at one year, were: direct effects of the initial hemorrhage ( $79 \%$ of affected patients), surgical complications $(13 \%)$, vasospasm (11\%), rebleeding (11\%) and medical complications (13\%). Conclusions: Almost two-thirds of patients suffering aneurysm rupture make a satisfactory recovery with modern treatment. While vasospasm has become a less common cause of poor outcome following $\mathrm{SAH}$, surgical complications remain an important problem.
\end{abstract}

RÉSUMÉ: Causes de morbidité et de mortalité suite à la rupture d'un anévrisme intracrânien. Objectif: Notre but était de déterminer le taux actuel de guérison et les causes de morbidité et de mortalité chez les patients ayant subi une hémorragie sous-arachnoïdienne due à un anévrisme (HSA). Méthodes: Nous avons revu une série récente de 95 patients consécutifs ayant subi une rupture d'anévrisme intracrânien et qui se sont présentés à notre hôpital entre 1994 et 1995. Quand un traitement était administré, il s'agissait d'une chirurgie précoce pour ligaturer l'anévrisme et de mesures agressives pour prévenir et traiter les complications reliées au HSA. Résultats: Quatre-vingt-huit (93\%) des patients avaient été admis dans les 24 heures suivant la rupture. Un quart des patients dans notre série n'ont pas subi de ligature de l'anévrisme à cause de leur mauvais état neurologique au moment de leur admission. Parmi les 75 patients initialement considérés éligibles à un traitement actif, $83 \%$ ont subi une chirurgie dans les 48 heures de la rupture; tous ont reçu de la nimodipine; $16 \%$ ont reçu de l'activateur du plasminogène tissulaire pour lyser des caillots sous-arachnoïdiens ou intraventriculaires; $40 \%$ ont reçu un traitement antihypertenseur et $7 \%$ ont subi une angioplastie transluminale pour vasospasme. À un an de suivi, $29 \%$ des patients étaient décédés, $7 \%$ avaient des déficits sévères, $13 \%$ avaient des déficits modérés, $51 \%$ avaient une bonne récupération et $64 \%$ de tous les survivants étaient retournés à leurs fonctions antérieures. Un an après l'événement, les causes principales de décès ou ayant contribué au décès, et les causes d'invalidité chez 47 patients étaient les effets directs de l'hémorragie initiale (79\% des patients), les complications chirurgicales (13\%), le vasospasme (11\%), une nouvelle hémorragie ( $11 \%)$ et des complications médicales (13\%). Conclusions: Presque les deux tiers des patients ayant subi une rupture d'anévrisme ont une récupération satisfaisante grâce à la thérapeutique moderne. Bien que le vasospasme soit devenu une cause moins fréquente de mauvais résultats suite à une HSA, les complications chirurgicales demeurent un problème important.

Can. J. Neurol. Sci. 1998; 25: 209-215

The management of intracranial aneurysm rupture and subarachnoid hemorrhage (SAH) continues to evolve, resulting in a perceived improvement in patient outcome. We wished to perform a critical examination of a recent series of patients with aneurysmal SAH managed in a uniform fashion with early microsurgery for aneurysm clipping and aggressive management of post-hemorrhagic complications in order to determine the current major causes of poor and impaired outcome following aneurysm rupture. A goal of this analysis was to obtain modern, overall, surgery-based management outcome results.

\section{Materials AND Methods}

A retrospective review of all patients with confirmed or highly probable aneurysmal SAHs presenting to the University of Alberta Hospital (Walter Mackenzie Health Sciences Centre site)

\footnotetext{
From the Division of Neurosurgery, University of Alberta, Edmonton.

RECEIVED FEBRUARY 20, 1998. ACCEPTED MARCH 18, 1998.

Reprint requests to: J. Max Findlay, Division of Neurosurgery, 2D1.02 W.C. Mackenzie Health Sciences Centre, 8440 - 112 Street, Edmonton, Alberta, Canada T6G 2B7
} 
between January 1994 and January 1995 was performed. This review included all patients with SAH and either an angiographically or autopsy confirmed cerebral aneurysm or, if angiography or postmortem examination was not performed, cranial computed tomographic (CT) scanning findings that were reported to be consistent with aneurysm bleeding (this observation subsequently confirmed by the authors). Patients were identified both from a neurosurgical data-base and a search in the hospital medical records department using a variety of appropriate diagnostic codes. Patients who arrived dead to the emergency room and were speculated to have possibly suffered a spontaneous intracranial hemorrhage were not included in this review. Patients with mycotic, traumatic and dissecting aneurysms were also excluded.

One of the authors (GMD), a former neurosurgical intensive care nurse trained in chart review and patient outcome assessment (clinical quality analysis), was employed by the hospital in a clinical quality improvement initiative and worked independently collecting the data for this study from both hospital and clinic charts, as well as from a telephone interview (to administer a verbal questionnaire) of all surviving patients.

This is not a population-based study, since during the study period patients suffering SAH in northern Alberta and the central Northwest Territories (the geographical area that is Edmonton's referral base for acute neurological diseases, population approximately 1.5 million) were also cared for at another Edmonton city hospital. However, the authors are unaware of any referral or selection bias for acute neurological patients existing between the two hospitals. In our city, during this time, patients with neurological emergencies were taken to the nearest hospital with neurosurgical coverage.

Demographic information, admission neurological status and SAH grades, ${ }^{1,2} \mathrm{CT}$ scan findings and, when it could be determined, aneurysm location were recorded for each patient. Outcome (using the Glasgow Outcome Scale ${ }^{3}$ ) as well as work-status assessments were made at three and twelve months from aneurysm rupture. All surviving patients had a follow-up clinical assessment both at approximately 3 and 6 months from rupture, and any patient with a less than good outcome at these intervals was also contacted by telephone for a follow-up interview at one year. For those patients who had either died or who were classified as having an impaired outcome at these two times primary and contributing causes of morbidity and mortality were established as specifically as possible. This was done using a checklist and examining the following eight aspects of the hospital and clinic charts: 1) the patient's neurological condition on admission; 2) clinically and/or radiologically documented rebleeding events prior to or following hospital admission; 3) the written and transcribed operative reports for descriptions of intraoperative complications; 4) any change from the preoperative to immediately postoperative neurological status; 5) all postoperative CT scan and cerebral angiography results, noting specifically descriptions of new hemorrhage, cerebral infarction or vascular occlusions; 6) the diagnosis of symptomatic cerebral vasospasm and/or vasospasm-related cerebral infarction, which required the delayed-onset of neurological deficits not due to other causes and confirmation by the results of transcranial Doppler testing, cerebral angiography or CT scans; 7) complications of hydrocephalus or its treatment (i.e., hemorrhage or infection); and 8) other, nonneurological complications (i.e., cardiac, pulmonary, gastrointestinal, and sepsis). The timing and nature of neurological deteriorations, and deaths, were ascribed to the most clearly identifiable primary cause, and all possible contributing causes were also noted. Deficits or death due to rebleeding had to be accompanied by radiological evidence of new hemorrhage, deficits due to surgery had to be noted immediately postoperatively and accompanied by an appropriate complication identifiable on CT scanning (infarct, hemorrhage, edema), and vasospasm-related events had to occur in a delayed fashion and accompanied by transcranial Doppler and/or angiographic confirmation of vasospasm. Deaths or deficits considered a direct effect of the initial bleeding were only of a neurological nature, and did not include cardiopulmonary complications unrelated to brainstem dysfunction.

All patients were managed by a single neurosurgical service which is also a training program for neurosurgical residents, and all operations were performed or supervised by one of three neurosurgeons, each of whom had been in clinical practice for more than five years with a special interest in aneurysm surgery. Management of ruptured aneurysms during the study period on this service, discussed in detail elsewhere, ${ }^{4,5}$ included a uniform preference for early microsurgical aneurysm clipping (within 24 hours of presentation) for all patients where a satisfactory outcome was felt possible, frequent use of external ventricular drainage, postoperative treatment in a neurointensive care unit with daily transcranial Doppler monitoring, routine use of postoperative cerebral angiography to assess aneurysm clipping and cerebral vasospasm, and measures to reduce cerebral vasospasm and vasospasm-related ischemia including administration of nimodipine to all patients, ${ }^{6.7}$ intraoperative, intracisternal tissue plasminogen activator in patients with thick SAHs, ${ }^{8}$ as well as a standard protocol for hypervolemia, induced hypertension and transluminal balloon angioplasty when appropriate for symptomatic patients. Patients with rapidly failing brainstem function and/or CT evidence of massive and vital brain destruction were not supported (other than maintenance as potential organ-donors), but poorer-grade patients (SAH grades 3 and $4^{\prime}$ ) less than 70 years of age without vital brain destruction or uncontrollable elevations in intracranial pressure were managed with early operation.

\section{Results}

A total of 95 patients with ruptured intracranial aneurysms were identified in the twelve month study period, 41 males and 54 females (male to female ratio 1:1.32), with ages ranging from 23 to 74 years (mean age 58 years). Presenting neurological conditions, admission CT findings and aneurysm locations are shown in Table 1. Eighty-eight (93\%) of the patients were admitted within 24 hours of rupture, and the remaining $7(7 \%)$ patients presented between one and five days following rupture. Thirty-seven patients (39\%) were SAH grades 4 or 5 , and 20 patients $(21 \%)$ did not undergo angiography (because of poor neurological condition) or postmortem examination to positively identify a responsible intracranial aneurysm.

A total of $56 \%$ of patients had associated intracerebral and/or intraventricular hemorrhages, and $15 \%$ had acute hydrocephalus. Twenty-four patients (25\%) did not undergo aneurysm 
Table 1: Clinical characteristics of study population $(n=95)$.

\begin{tabular}{|c|c|c|}
\hline Admission Neurological Status & $\#$ & $\%$ \\
\hline Headache & 22 & 23 \\
\hline Severe headache but alert & 14 & 15 \\
\hline Drowsy & 22 & 23 \\
\hline Semi-comatose or comatose & 21 & 22 \\
\hline Moribund & 16 & 17 \\
\hline Admission CT Findings* & $\#$ & $\%$ \\
\hline Intracerebral hemorrhage & 34 & 36 \\
\hline Intraventricular hemorrhage & 19 & 20 \\
\hline Hydrocephalus & 14 & 15 \\
\hline Infarction (acute) & 1 & 1 \\
\hline Thick, diffuse subarachnoid clots & 27 & 28 \\
\hline Aneurysm Location & $\#$ & $\%$ \\
\hline Internal carotid artery & 22 & 23 \\
\hline Anterior cerebral artery & 23 & 24 \\
\hline Middle cerebral artery & 16 & 17 \\
\hline Vertebrobasilar arteries & 12 & 13 \\
\hline None positively identified** & 20 & 21 \\
\hline Surgical Procedures & \# & $\%$ \\
\hline Aneurysm clipping & 71 & 75 \\
\hline Hematoma evacuation (only) & 1 & 1 \\
\hline VP shunt insertion & 3 & 3 \\
\hline None & 23 & 24 \\
\hline
\end{tabular}

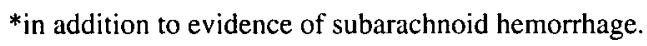

**angiography and postmortem examination not performed, but clinical features and $\mathrm{CT}$ results consistent with intracranial aneurysm rupture.

repair, although one of these patients underwent emergency evacuation of an intracerebral hemorrhage but died prior to aneurysm treatment. There was only one giant aneurysm in this series, an anterior communicating artery aneurysm with a length of $28 \mathrm{~mm}$.

Some aspects of patient management are shown in Table 2. Of the 75 patients who underwent diagnostic cerebral angiography following presentation and therefore in whom there was an initial interest in active treatment, $62(83 \%)$ underwent aneurysm clipping within 48 hours of rupture, and $72(96 \%)$ ultimately underwent aneurysm clipping. All of these 75 patients received nimodipine, $10(13 \%)$ received intraoperative intracisternal rt-PA for vasospasm prophylaxis, $4(5 \%)$ received intraventricular $\mathrm{rt}$ PA for intraventricular clot lysis, $30(40 \%)$ received an infusion of an inotropic and/or vasopressor at some point, and $5(7 \%)$ patients underwent transluminal balloon angioplasty for symptomatic cerebral vasospasm despite hypervolemic, hypertensive therapy. Seventy-one of the 72 patients who underwent aneurysm
Table 2: Details of patient management.

\begin{tabular}{lcc}
\hline Treatment Characteristic & $\#$ & $\% *$ \\
\hline Surgery within 48 hours of rupture & 62 & 83 \\
\hline Perioperative ventricular drainage & 51 & 68 \\
\hline Inotrope and/or vasopressor infusion & 30 & 40 \\
\hline
\end{tabular}

Tissue plasminogen activator administration - subarachnoid

10 13

\begin{tabular}{lcc}
\hline - intraventricular & 4 & 5 \\
\hline Postoperative cerebral angiography & 71 & 95 \\
\hline Reoperation for aneurysm remnant & 3 & 4 \\
\hline
\end{tabular}

${ }^{*} \mathrm{n}=75$ patients who received "active treatment" (see text)

Table 3: Glasgow outcome scores $(n=95)$.

\begin{tabular}{lcccc}
\hline \multirow{2}{*}{ Glasgow Outcomes } & \multicolumn{2}{c}{$\mathbf{3}$ mo } & \multicolumn{2}{c}{12 mo } \\
\cline { 2 - 5 } & $\#$ & $\%$ & $\#$ & $\%$ \\
\hline Deceased & 26 & 27 & 28 & 29 \\
\hline Vegetative state & 1 & 1 & 0 & 0 \\
\hline Severe disability & 11 & 12 & 7 & 7 \\
\hline Moderate disability & 13 & 14 & 12 & 13 \\
\hline Good recovery & 44 & 46 & 48 & 51 \\
\hline
\end{tabular}

Table 4: Work status of surviving patients.

\begin{tabular}{lccccc}
\hline \multirow{2}{*}{ Work Status } & \multicolumn{2}{c}{$3 \mathrm{mo}$} & \multicolumn{2}{c}{$12 \mathrm{mo}$} \\
\cline { 2 - 6 } & $\#$ & $\%$ & $\#$ & $\%$ \\
\hline Returned to previous work & 26 & 38 & 43 & 64 \\
\hline $\begin{array}{l}\text { Not returned to previous work due } \\
\text { to persistent neurological deficit }\end{array}$ & 35 & 51 & 18 & 27 \\
\hline $\begin{array}{l}\text { Not returned to previous work } \\
\text { due to other reasons }\end{array}$ & 8 & 11 & 6 & 9 \\
\hline Total & 69 & & 67 & \\
\hline
\end{tabular}

repair also had postoperative cerebral angiography. Unequivocal aneurysm remnant (radiologist and surgeon in agreement) was found in $6(8 \%)$ of these patients, and 3 patients subsequently underwent reoperation for aneurysm remnant obliteration.

Glasgow outcome scores and work-status for the patient population are shown in Tables 3 and 4, respectively. Follow-up was obtained for every patient. Twenty-eight patients (29\%) died, 26 of these by 3 months. The single vegetative patient at the 3 month follow-up died 6 months from hemorrhage, and another patient with severe disabilities died of myocardial failure at 5 months. Overall favorable (good and moderate disability): unfavorable (death, vegetative and severe disability) outcome ratios were 60\%:40\% at 3 months and $64 \%: 36 \%$ at one year. Three patients improved from severe to moderate disabilities and four patients improved from moderate disabilities to good outcome in the 3 to 12 month interval, 
Table 5: Patient outcomes, one year follow-up $(n=95)$.

\begin{tabular}{lcccccc}
\hline \multirow{2}{*}{ Outcome* } & \multicolumn{7}{c}{ Admission Neurological Grade (WFNS) } \\
\cline { 2 - 8 } & I & II & III & IV & V & Total \\
\hline Favorable & 21 & 11 & 17 & 11 & 0 & 60 \\
\hline Unfavorable & 1 & 3 & 5 & 10 & 16 & 35 \\
\hline
\end{tabular}

* favorable $=$ Glasgow outcomes good and moderate disabilities; unfavorable $=$ severe disability, vegetative state and death.

Table 6: Primary and contributing causes of death.

\begin{tabular}{|c|c|c|c|c|}
\hline \multirow{2}{*}{ Primary Cause of Death } & \multicolumn{2}{|c|}{3 mo } & \multicolumn{2}{|c|}{$12 \mathrm{mo}$} \\
\hline & \# & $\%$ & \# & $\%$ \\
\hline Direct effect of initial bleed & 18 & 69 & 19 & 67 \\
\hline Rebleeding & 4 & 15 & 4 & 14 \\
\hline Cerebral infarct, surgical complication & 3 & 12 & 3 & 11 \\
\hline GI complication & 1 & 4 & 1 & 4 \\
\hline Cardiac complication & 0 & 0 & 1 & 4 \\
\hline Total & 26 & & 28 & \\
\hline \multirow{2}{*}{ Contributing Cause of Death } & \multicolumn{2}{|c|}{3 mo } & \multicolumn{2}{|c|}{$12 \mathrm{mo}$} \\
\hline & \# & $\%$ & \# & $\%$ \\
\hline Direct effect of initial bleed & 3 & 12 & 3 & 11 \\
\hline Rebleeding & 1 & 4 & 1 & 4 \\
\hline Cerebral infarct, vasospasm complication & 2 & 8 & 2 & 8 \\
\hline Cerebral infarct, surgical complication & 1 & 4 & 1 & 4 \\
\hline Hydrocephalus & 1 & 4 & 1 & 4 \\
\hline Pulmonary complication & 1 & 4 & 1 & 4 \\
\hline Sepsis complication & 1 & 4 & 2 & 8 \\
\hline
\end{tabular}

but no patient moved from the severe disability to good outcome group. Outcome at one year correlated with admission neurological status (Table 5). Twenty-six of 69 surviving patients at three months (38\%) had returned to work by 3 months from hemorrhage, and this increased to $64 \%$ of one-year survivors.

The leading primary cause of death was the direct effects of initial aneurysm bleeding, responsible for 18 of $26(69 \%)$ deaths at 3 months and 19 of 28 deaths $(67 \%)$ at one year (Table 6). Far behind this, but close to each other, were the consequences of aneurysm rebleeding (4 deaths at one year) and cerebral infarction resulting from complications of surgery (3 deaths at one year). Cerebral vasospasm was not a primary cause of death in this series but contributed to the death of 2 patients (7\%).

Similarly, the leading primary cause of morbidity in this series was the direct effect of aneurysm bleeding, which was responsible for 16 of the 25 disabilities (64\%) at 3 months and 14 of 19 disabilities (74\%) that remained at one year (Table 7). Vasospasm accounted for $16 \%$ of disabilities at one year, while surgical complications caused $10 \%$ of disabilities still present at one year. Of the five rebleeding events that occurred four were prior to aneurysm repair and were primarily responsible for all four patients' deaths, and one resulted from an aneurysm rem-
Table 7: Primary and contributing causes of disability.

\begin{tabular}{lcccc}
\hline \multirow{2}{*}{ Primary Cause of Disability } & \multicolumn{2}{c}{3 mo } & \multicolumn{2}{c}{12 mo } \\
\cline { 2 - 6 } & $\#$ & $\%$ & $\#$ & $\mathbf{\%}$ \\
\hline Direct effect of initial bleed & 16 & 64 & 14 & 74 \\
\hline Cerebral infarct, vasospasm complication & 4 & 16 & 3 & 16 \\
\hline Cerebral hemorrhage, surgical complication & 1 & 4 & 1 & 5 \\
\hline Cerebral infarct, surgical complication & 3 & 12 & 1 & 5 \\
\hline Cardiac complication & 1 & 4 & 0 & 0 \\
\hline Total & $\mathbf{2 5}$ & & 19 & \\
\hline Contributing Cause of Disability & $\mathbf{3}$ mo & $\mathbf{1 2} \mathbf{~ m o}$ \\
\cline { 2 - 6 } & $\#$ & $\%$ & $\#$ & $\%$ \\
\hline Direct effect of initial bleed & 1 & 4 & 1 & 4 \\
\hline Hydrocephalus & 2 & 8 & 1 & 4 \\
\hline Cardiac complication & 2 & 8 & 1 & 4 \\
\hline
\end{tabular}

Table 8: Primary or contributing cause of death or disability, one year follow-up.

\begin{tabular}{lcc}
\hline Primary or Contributing Cause & $\#$ & \% \\
\hline Direct effect of initial bleed & 37 & 79 \\
\hline Surgical complication & 6 & 13 \\
\hline Cerebral infarct, vasospasm complication & 5 & 11 \\
\hline Rebleeding & 5 & 11 \\
\hline Hydrocephalus & 2 & 4 \\
\hline Medical complication & 6 & 13 \\
\hline
\end{tabular}

nant that was subsequently identified by cerebral angiography and repaired. This patient also subsequently died, partly due to the rebleeding event, but secondary also to vasospastic cerebral infarction and pulmonary sepsis. The figures for combined primary and contributing causes of both death and disability at the one year follow-up are shown in Table 8. Overall, surgical complications slightly exceeded both the effects of aneurysm rebleeding and vasospasm as a cause of death or disability.

\section{Discussion}

\section{Outcome Assessment}

An important limitation of this study, and one shared with most other outcome studies examining $\mathrm{SAH},{ }^{9-18}$ is dependency on the Glasgow outcome scale or similar outcome classification. Popular because it is practical and easy to apply, and reliable in interobserver studies, ${ }^{19}$ the GOS nevertheless classifies patients broadly according mainly to motor impairment, and it fails to detect less obvious impairments in higher cerebral functions, including memory and cognition. More thorough neuropsychological examinations have found these types of deficits common following $\mathrm{SAH},{ }^{20-23}$ and depending upon the cerebral function tested, present in over one-half of even GOS "good outcome" SAH survivors. ${ }^{24.25}$ Others, however, have not found that these 
more subtle deficits significantly reduce many patients' quality of life. ${ }^{26}$ Despite this important limitation, most investigators believe that the GOS provides clinically useful summary information in an observational study such as ours where additional, labor intensive, neurological or neuropsychological testing is beyond its scope. Our study did demonstrate the usefulness of an at least one year follow-up in outcome assessment, since between 3 and 12 months two patients died, and a total of $7(7 \%)$ patients improved one grade in the Glasgow Outcome Scale.

\section{SAH Outcome Studies}

The outcome results of this study should be distinguished from reports of strictly surgical aneurysm series, where patients in better neurological condition are selected to undergo operative therapy and the publications are usually intended to demonstrate the advantage of a specific surgical or management approach. ${ }^{27}$ The overall results of those studies are usually more optimistic. On the other hand, our study cannot be compared directly to large epidemiological studies where all, or nearly all, patients suffering $\mathrm{SAH}$ in a certain time period within a defined geographical region are entered. ${ }^{12.15,16,18.28}$ These studies are particularly useful in defining the incidence and case-fatality rates for $\mathrm{SAH}$ in a region. Because smaller clinic-based series can be examined in detail, and results considered to reflect a uniform management strategy, we believe that our analysis and similar studies ${ }^{10,13,17}$ provide useful clinical information.

The results of smaller clinic-based studies are often compared to the findings of the International Cooperative Study on the Timing of Aneurysm Surgery, ${ }^{29}$ which as part of its analysis documented the overall management results of 3521 patients treated between 1980 and 1983 . Not all patients were eligible for entry into that study, so that a high percentage (between $75 \%$ and $80 \%$ of patients) were in good neurological condition upon entry. Overall, favorable outcomes were seen in $67 \%$ of patients, and unfavorable outcomes in $33 \%$. The leading causes of death and disability were, in the overall analysis and in descending order: vasospasm $(14 \%)$, the direct effects of the initial insult (11\%), rebleeding (8\%), and surgical complications $(4 \%)$.

More recent studies have found that vasospasm has become a less common cause for poor outcome, that primary effects of the hemorrhage predominate when the patient populations are unselected, and surgical complications are more common than seen in the Cooperative Timing Study. Säveland et al. prospectively evaluated the results of a uniform management protocol in 325 unselected patients admitted to 5 neurosurgical units in Sweden between 1989 and $1990 . .^{13}$ Overall, at 3 to 6 months follow-up, $56 \%$ of patients were classified as having a good outcome, $23 \%$ had some morbidity, and $21 \%$ had died. Of the 142 patients with some residual morbidity and classified as an unfavorable outcome, $46 \%$ were due to the initial bleed, $14 \%$ were due to surgical trauma, $14 \%$ were due to rebleeding, $13 \%$ were due to vasospasm, and $8 \%$ were due to medical complications. Only $5.5 \%$ of the 248 patients who presented in good neurological condition suffered morbidity secondary to vasospasm, which the authors attributed to their policy of early aneurysm surgery and aggressive anti-ischemic treatment.

Proust et al. examined 230 consecutive patients admitted to a single neurosurgical unit in Rouen, France, between 1987 and 1993. ${ }^{17}$ Two hundred of these patients were in "good" preoperative neurological condition (SAH grades I-III). At a 6-12 month follow-up a total of $77 \%$ of patients achieved a good outcome,
$7 \%$ were disabled, and $16 \%$ were either vegetative or dead. In that selected aneurysm series, where early surgery and aggressive vasospasm treatments including nimodipine, transcranial Doppler monitoring, and hypervolemia were employed, the leading cause of impaired outcome was surgical complications (mostly ischemia resulting from an arterial occlusion), affecting $11 \%$ of patients, followed by effects of the initial hemorrhage (10\%), and vasospasm (4\%). Considering just the 200 patients in good preoperative neurological condition, the leading cause of impaired outcome was again a surgical complication, which was seen in $20 \%$ of patients in that group. Surgical complications accounted for $38 \%$ of all disabilities and deaths in that study. The authors attributed this higher surgical complication rate compared to previous studies (such as the Cooperative Timing Study) to a higher detection rate resulting in part from their routine use of postoperative angiography.

\section{Results, Limitations and Usefulness of the Present Study}

The result of our relatively small series are in agreement with previous indications that the effects of vasospasm on SAH outcome have been reduced in recent years. ${ }^{13.15 .17}$ The most probable explanation for this has been improved vasospasm prevention and treatment, and the vasospasm treatments used in our study population reflect modern SAH management as it is commonly practiced in modern neurosurgical units in North America. ${ }^{5,30}$ One exception to this is our unit's use of tissue plasminogen activator for lysis of thick subarachnoid or intraventricular clots (used in a total of 12 patients in this series), since this has not become a widely adopted practice in North America. However, while possibly simplifying the management of this small subgroup of patients, it is unlikely that the use of plasminogen activator in this series of patients had a significant effect on overall patient outcome. According to our results it would appear that vasospasm currently accounts for or contributes to about $10 \%$ of SAH-related morbidity and mortality in our unselected neurosurgical series of patients, and directly results in death or permanent morbidity in only about $5 \%$ of the entire patient population. While vasospasm clearly remains an important clinical problem, demanding early recognition and prompt intervention, improvements in prevention and treatment strategies within the last two decades have significantly reduced its permanent effects on SAH populations. On the other hand, the often devastating neurological consequences of the initial hemorrhage continue to predominate as the major cause of poor outcome. In addition to the direct parenchymal injury that severe aneurysm bleeding can inflict locally, sudden and large increases in intracranial pressure associated with aneurysm rupture can result in a profound reduction in cerebral perfusion and global ischemic brain damage. Aside from preventing these same injuries resulting from aneurysm rebleeding through early aneurysm repair, we can only ameliorate primary SH injury by providing an optimal physiological environment for neural recovery. Surgical complications, when specifically searched for, emerge as an important cause of poor outcome, accounting for $14 \%$ of combined morbidity and mortality, and permanently affecting $11 \%$ of all operated patients in our series. We believe this rate, higher than in many previous studies, is not due to inferior surgery, but rather due to clear criteria followed to distinguish delayed vasospasm-related ischemic deterioration from postoperative cerebral ischemia due to inadvertent vascular 
occlusion, the use of an unbiased, "third-party", data collector rather than the operating surgeon, and finally the inherent difficulty of operating on acutely ruptured intracranial aneurysms, even in the era of microneurosurgery. The ischemic complications of surgery in this series were a combination of both large vessel and perforator occlusions. Improvements in surgical technique will bring these complications to a certain irreducible figure, but to completely avoid surgical risks, alternate, endovascular methods of aneurysm ablation have to be considered.

Our study is not large enough to draw statistical conclusions regarding the effects of such things as age, ${ }^{31}$ gender, ${ }^{32.33}$ aneurysm location or characteristic, and various other variables which have been shown to affect SAH outcome in large studies. ${ }^{15,29}$ Ours is a single-institution retrospective review, subject to all of the short-falls of such a study, and it undoubtedly missed SAHs seen at our hospital during the study period, including those patients who arrived to the emergency department dead. The fatality rate we found in this series, $30 \%$ at one year, is below the $40 \%$ to $50 \%$ case-fatality rate that has been found in several recent epidemiological studies. ${ }^{12.15 .28}$

However, these results do provide a local and recent baseline for the overall and microsurgical management results for aneurysmal SAH diagnosed in our hospital, against which newer treatments, including endovascular coil embolization of aneurysm sacs, can be compared in an uncontrolled fashion. Recent reports indicate that with sufficient experience the acute complication rates (hemorrhage, thrombosis) associated with aneurysm coil occlusion will potentially equal, and for some aneurysm locations and types probably even improve upon microsurgical results such as described in our series. ${ }^{34-45}$ It may be that the more important criterion for the usefulness of embolic materials for aneurysm treatment will be their long-term effectiveness and the permanence of aneurysm occlusions achieved in this way. It is hoped that controlled studies comparing endovascular and surgical aneurysm repair will answer some of these important questions.

\section{ACKNOWLEDGEMENTS}

The authors thank Ms. Arlene MacLean for the preparation of this manuscript.

\section{REFERENCES}

1. Drake CG. Report of World Federation of Neurological Surgeons committee on a universal subarachnoid hemorrhage grading scale (Neurosurgical forum). J Neurosurg 1988; 68: 985-986.

2. Lougheed WM, Marshall BM. Management of aneurysms of the anterior circulation by intracranial procedures. In: Youmans JR, ed. Neurological Surgery, Philadelphia: WB Saunders, Publisher 1973; 3: 731-767.

3. Jennett B, Bond M. Assessment of outcome after severe brain damage. A practical scale. Lancet 1975; 1: 480-484.

4. Findlay JM. Perioperative management of subarachnoid hemorrhage. Contemp Neurosurg 1995; 17: 1-6.

5. Findlay JM and a CNS practice guidelines review group. Current management of aneurysmal subarachnoid hemorrhage. Guidelines from the Canadian Neurosurgical Society. Can J Neurol Sci 1997; 24: 161-170.

6. Robinson MJ, Teasdale GM. Calcium antagonists in the management of subarachnoid haemorrhage. Cerebrovasc Brain Met Rev 1990; 2: 205-226.

7. Barker FG, Ogilvy CS. Efficacy of prophylactic nimodipine for delayed ischemic deficit after subarachnoid hemorrhage: a metaanalysis. J Neurosurg 1996; 84: 405-414.
8. Findlay JM, Kassell NF, Weir BKA, et al. A randomized trial of intraoperative, intracisternal tissue plasminogen activator for the prevention of vasospasm. Neurosurgery 1995; 37: 168-178.

9. Sundt TM Jr, Whisnant JP. Subarachnoid hemorrhage from intracranial aneurysms. Surgical management and natural history of disease. N Engl J Med 1978; 299: 116-122.

10. Hijdra A, Braakman R, van Gijn J, Vermeulen M, van Crevel $H$. Aneurysmal subarachnoid hemorrhage: complications and outcome in a hospital population. Stroke 1987; 18: 1061-1067.

11. Kassell NF, Torner JC, Jane JA, and participants. The International Cooperative Study on the timing of aneurysm surgery. Part 2: Surgical results. J Neurosurg 1990; 73: 37-47.

12. Sarti C, Tuomilehto J, Salomaa V, et al. Epidemiology of subarachnoid hemorrhage in Finland from 1983 to 1985. Stroke 1991; 22: 848-853.

13. Säveland H, Hillman J, Brandt L, et al. Overall outcome in aneurysmal subarachnoid hemorrhage: a prospective study from neurosurgical units in Sweden during a 1-year period. J Neurosurg 1992; 76: 729-734.

14. Haley EC Jr, Kassell NF, Torner JC, and the participants. The International Cooperative Study on the timing of aneurysm surgery: the North American experience. Stroke 1992; 23: 205-214.

15. Broderick JP, Brott TG, Duldner JE, Tomsick T, Leach A. Initial and recurrent bleeding are the major causes of death following subarachnoid hemorrhage. Stroke 1994; 25: 1342-1347.

16. Inagawa $\mathrm{T}$, Tokuda $\mathrm{Y}$, Ohbayashi N, Takaya M, Moritake K. Study of aneurysmal subarachnoid hemorrhage in Izumo City, Japan. Stroke 1995; 26: 761-766.

17. Proust F, Hannequin D, Langlois O, Freger P, Creissard P. Causes of morbidity and mortality after ruptured aneurysm surgery in a series of 230 patients: the importance of control angiography. Stroke 1995; 26: 1553-1557.

18. Tolias CM, Choksey MS. Will increased awareness among physicians of the significance of sudden agonizing headache affect the outcome of subarachnoid hemorrhage? Coventry and Warwickshire Study: audit of subarachnoid hemorrhage (establishing historical controls), hypothesis, campaign layout, and cost estimation. Stroke 1996; 27: 807-812.

19. van Gijn J, Bromberg JEC, Lindsay KW, Hasan D, Vermeulen M. Definition of initial grading, specific events, and overall outcome in patients with aneurysmal subarachnoid hemorrhage: a survey. Stroke 1994; 25: 1623-1627.

20. Ljunggren B, Sonesson BS, Säveland H, Brandt L. Cognitive impairment and adjustment in patients without neurological deficits after aneurysmal SAH and early operation. J Neurosurg 1985; 62: 673-679.

21. Bornstein RA, Weir BKA, Petruk KC, Disney LB. Neuropsychological function in patients after subarachnoid hemorrhage. Neurosurgery 1987; 21: 651-654.

22. Vilkki J, Holst P, Ohman J, Servo A, Heiskanen O. Cognitive deficits related to computed tomographic findings after surgery for a ruptured intracranial aneurysm. Neurosurgery $1989 ; 25$ : 166-172.

23. Richardson JTE. Cognitive performance following rupture and repair of intracranial aneurysm. Acta Neurol Scand 1991; 83: 110-122.

24. Ogden JA, Mee, EW, Henning M. A prospective study of impairment of cognition and memory and recovery after subarachnoid hemorrhage. Neurosurgery 1993; 33: 572-587.

25. Hütter B-O, Gilsbach J-M. Which neuropsychological deficits are hidden behind a good outcome (Glasgow = I) after aneurysmal subarachnoid hemorrhage? Neurosurgery 1993; 33: 999-1006.

26. McKenna P, Willison JR, Lowe D, Neil-Dwyer G. Cognitive outcome and quality of life one year after subarachnoid haemorrhage. Neurosurgery 1989; 24: 361-367.

27. Le Roux PD, Elliott JP, Downey L, et al. Improved outcome after rupture of anterior circulation aneurysms: a retrospective 10-year review of 224 good-grade patients. J Neurosurg 1995; 83: 394-402.

28. Ingall TJ, Whisnant JP. Has there been a decline in subarachnoid hemorrhage mortality? Stroke 1989; 20: 718-724.

29. Kassell NF, Torner JC, Haley C Jr, and participants. The International Cooperative Study on the timing of aneurysm surgery. Part 1: Overall management results. J Neurosurg 1990; 73: 18-36. 
30. Mayberg MR, Batjer HH, Dacey R, and members. Guidelines for the management of aneurysmal subarachnoid hemorrhage. A statement for healthcare professionals from a special writing group of the Stroke Council, American Heart Association. Circulation 1994; 90: 2592-2605.

31. Stachniak JB, Layon AJ, Day AL, Gallagher J. Craniotomy for intracranial aneurysm and subarachnoid hemorrhage. Is course, cost, or outcome affected by age? Stroke 1996; 27: 276-281.

32. Disney L, Weir B, Grade M, and the Canadian Nimodipine Study Group. Factors influencing the outcome of aneurysm rupture in poor grade patients: a prospective series. Neurosurgery 1988; 23 : $1-9$.

33. Kongable GL, Lanzino G, Germanson TP, and participants. Gender-related differences in aneurysmal subarachnoid hemorrhage. J Neurosurg 1996; 84: 43-48.

34. Guglielmi G, Vinuela F, Sepetka I, Macellari V. Electrothrombosis of saccular aneurysms via endovascular approach, Part 1: Electrochemical basis, technique, and experimental results. J Neurosurg 1991; 75: 1-7.

35. Guglielmi G, Vinuela F, Dion J, Duckwiler G. Electrothrombosis of saccular aneurysms via endovascular approach, Part 2: Preliminary clinical experience. J Neurosurg 1991; 75: 8-14.

36. Guglielmi G, Vinuela F, Duckwiler G, et al. Endovascular treatment of posterior circulation aneurysms by electrothrombosis using electrically detachable coils. J Neurosurg 1992; 77: 515524.
37. Casasco A, Aymard A, Gobin P, et al. Selective endovascular treatment of 71 intracranial aneurysms with platinum coils. J Neurosurg 1993; 79: 3-10.

38. Halbach V, Higashida R, Dowd C, et al. The efficacy of endosaccular aneurysm occlusion in alleviating neurological deficits produced by mass effect. J Neurosurg 1994; 80: 659-666.

39. Zubillaga A, Guglielmi G, Vinuela F, Duckwiler G. Endovascular occlusion of intracranial aneurysms with electrically detachable coils. Am J Neuroradiol 1994; 15: 815-820.

40. Mawad M, Mawad J, Cartwright J, Gokaslan Z. Long-term histopathologic changes in canine aneurysms embolized with Guglielmi detachable coils. Am J Neuroradiol 1995; 16: 7-13.

41. Nichols D. Endovascular treatment of the acutely ruptured intracranial aneurysm. J Neurosurg 1995; 79: 1-2.

42. Graves VB, Strother CM, Duff TA, Perl J II. Early treatment of ruptured aneurysms with Guglielmi detachable coils: effect on subsequent bleeding. Neurosurgery 1995; 37: 640-648.

43. Gobin YP, Vinuela F, Gurian JH, et al. Treatment of large and giant fusiform intracranial aneurysms with Guglielmi detachable coils. J Neurosurg 1996; 84: 55-62.

44. McDougall CG, Halbach W, Dowd CF, et al. Endovascular treatment of basilar tip aneurysms using electrolytically detachable coils. J Neurosurg 1996; 84: 393-399.

45. Pierot L, Boulin A, Castaings L, Rey A, Moret J. Selective occlusion of basilar artery aneurysms using controlled detachable coils: report of 35 cases. Neurosurgery 1996; 38: 948-954. 